\title{
Size sorting of chemically modified graphene nanoplatelets
}

\author{
Joong Tark Han, Jeong In Jang, Sung Hun Kim, Seung Yol Jeong, Hee Jin Jeong and Geon-Woong Lee \\ Nano Carbon Materials Research Group, Creative and Fundamental Research Division, Korea Electrotechnology Research Institute, \\ Changwon 642-120, Korea
}

\section{Article Info \\ Received 18 February 2013 \\ Accepted 25 March 2013 \\ *Corresponding Author \\ E-mail: gwleephd@keri.re.kr \\ Open Access \\ DOI: http://dx.doi.org/ \\ 10.5714/CL.2013.14.2.089 \\ This is an Open Access article distributed under the terms of the Creative Commons Attribution Non-Commercial License (http://creativecommons.org/licenses/ by-nc/3.0/) which permits unrestricted non-commercial use, distribution, and reproduction in any medium, provided the original work is properly cited.}

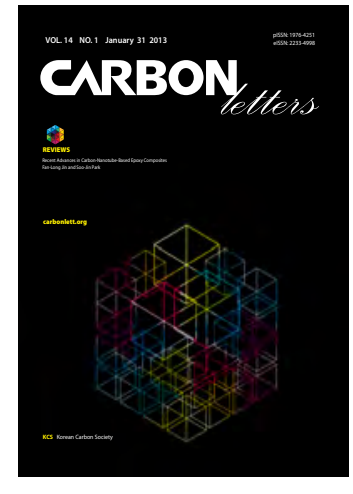

http://carbonlett.org

pISSN: $1976-4251$

elSSN: 2233-4998

Copyright $\odot$ Korean Carbon Society

\begin{abstract}
Size-sorted graphene nanoplatelets are highly desired for fundamental research and technological applications of graphene. Here we show a facile approach for fabricating size-sorted graphene oxide (GO) nanoplatelets by a simple centrifugal method using different dispersion solvents. We found that the small-sized GO nanoplatelets were more effectively separated when dispersed in water or dimethylformamide (DMF) than in an alkali aqueous solution. After several iterations of the centrifugation, the sizes of GO in the supernatant solution were mostly several micrometers. We found that the GO area was not strongly correlated with the $\mathrm{C}-\mathrm{O}$ content of the GO dispersed in water. However, the size-sorted GO nanoplatelets in DMF showed different C-O content, since DMF can reduce GO nanoplatelets during exfoliation and centrifugation processes.
\end{abstract}

Key words: graphene, size sorting, centrifugation

\section{Introduction}

Chemically modified graphene, which is produced through the oxidation of highly oriented pyrolytic graphite, is composed of typical two-dimensional (2D) particles and is attracting a great deal of interest in colloidal sciences [1-14]. The solution processability of graphene oxide (GO) permits application of GO to substrates via spin-coating, spray-casting, drop-casting, or inkjet printing for large-scale production of graphene electronic circuits. Subsequent reduction of GO nanoplatelets can proceed through deoxygenation by chemical reduction or by thermal routes for recovery of their electrical properties.

GO nanoplatelets can be generated by chemical exfoliation of graphite with strong acid treatment, a technique introduced by Hummers and Brodie. Epoxy and hydroxyl groups are formed in the basal plane and carbonyl and carboxylic acid groups in the edge sites [15]. Due to the presence of hydrophilic functional groups, GO nanoplatelets are easily dispersed and exfoliated in an aqueous solution or organic solvent by sonication or shearing with a homogenizer. The oxidation and exfoliation processes produce diverse sizes of GO nanoplatelets. The electrical conductivities of chemically-modified graphene nanoplatelets depend on the defect level and the sheet size [12]. Furthermore, small-sized GO nanoplatelets can be used as a p-type dopant and surface modifier of a single-walled carbon nanotube electrode [16]. Therefore, the method used to separate the small-sized or large-sized graphene nanoplatelets is an important issue for allowing diverse application of chemically-modified graphene.

Here, we report a facile method for size-sorting of GO nanoplatelets dispersed in various solvents by a simple centrifugal method. Graphite oxide was exfoliated into GO in various solvent media. We found that various GO sizes can be obtained depending on the centrifugal process and the dispersion solvent. 


\section{Experimental}

\subsection{Materials}

GO nanoplatelets were prepared via the exfoliation of graphite oxide powder, which was produced from natural graphite (Alfa Aesar, 99.999\% purity, -200 mesh) using a modified Hummers method. Briefly, $20 \mathrm{~g}$ of graphite and $460 \mathrm{~mL}$ of $\mathrm{H}_{2} \mathrm{SO}_{4}$ were mixed in a flask. Then, $60 \mathrm{~g}$ of $\mathrm{KMnO}_{4}$ was added slowly, over a period of approximately $1 \mathrm{~h}$. Stirring was continued for $2 \mathrm{~h}$ in an ice-water bath. After the mixture was stirred vigorously for 3 days at room temperature, $920 \mathrm{~mL}$ of deionized water was added, and stirring proceeded for $10 \mathrm{~min}$ in an icewater bath. Fifty milliliters of $\mathrm{H}_{2} \mathrm{O}_{2}$ ( $30 \mathrm{wt} \%$ aqueous solution) was then added, and the mixture was stirred for $2 \mathrm{~h}$ at room temperature. The resulting mixture was precipitated and filtered to obtain the graphite oxide powder. The graphite oxide powder was dispersed in water by magnetic stirring, and the highly functionalized graphite oxide with carboxylic acid groups was removed by centrifugation of a $2 \mathrm{~g} / \mathrm{L}$ aqueous $\mathrm{GO}$ solution. The sediment graphite oxide solution was free-dried and redispersed in deionized water, alkali solution ( $\mathrm{pH} \sim 11$, adjusted by potassium hydroxide $[\mathrm{KOH}]$ ), and dimethylformamide (DMF) to a concentration of $500 \mathrm{mg} / \mathrm{L}$ by bath sonication for $1 \mathrm{~h}$ to exfoliate the graphite oxide into GO nanoplatelets. The GO nanoplatelets were sorted using centrifugation at $10000 \mathrm{rpm}$ for $1 \mathrm{~h}$, and the supernatant solution was then decanted. The sediment was redispersed in the used solvents to the same volume, and the centrifugation and decanting steps were repeated to prepare size-sorted GO nanoplatelets. The supernatant solution was concentrated and freeze-dried to obtain a powder for characterization.

\subsection{Characterization}

Images of the resulting films were obtained using scanning electron microscopy (SEM, HITACHI S4800). The structural characteristics of the reduced GO (RGO) sheets were investigated by a confocal Raman spectrometer (NTEGRA SPECTRA, NT-MDT) with an excitation wavelength of $532 \mathrm{~nm}$. To confirm the change in the carbon to oxygen atomic ratio in the functional groups of the films after reduction by hydrazine molecules synthesized in-situ, an X-ray photoelectron spectroscopy (XPS) analysis was conducted using a Multilab2000 (Thermo VG Scientific Inc.) spectrometer with monochromatized Al K X-ray radiation as the X-ray excitation source. A Fourier infrared (FTIR) spectroscopy (JASCO, 4200UP) analysis was performed to assign the functional group of the GO nanoplatelets.

\section{Results and Discussion}

GO nanoplatelets were prepared by exfoliation of graphite oxide produced by the modified Hummers method using pure graphite (with an average size of $70 \mu \mathrm{m}$ from natural graphite powder). Figs. 1a and b show FTIR and XPS spectra of graphite oxide, where epoxy, hydroxyl, and carbonyl groups have been assigned. Prior to the sorting process, the highly carboxylated graphite oxide (which was highly dispersible in water) was re-
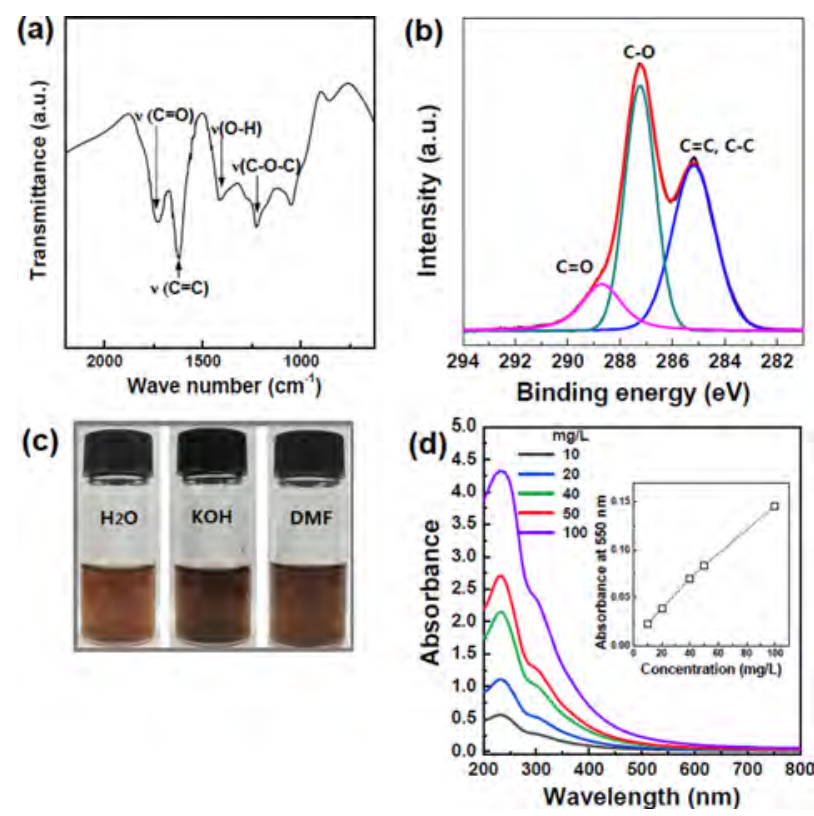

Fig. 1. (a) Fourier infrared spectrum of graphite oxide powder. (b) UV absorbance spectra of graphene oxide (GO) dispersion in deionized water as a function of the concentration. (c) Photo images of GO solutions in vials. (d) X-ray photoelectron spectroscopy spectrum of graphite oxide.

moved by decanting the supernatant during the washing process; the carboxylated large-sized GO nanoplatelets would not have been separated from the small-sized GO nanosheets during centrifugation. A homogeneous colloidal suspension of GO nanoplatelets was prepared in deionized water $\left(\mathrm{H}_{2} \mathrm{O}\right)$, alkali solution $(\mathrm{KOH})$, and DMF at a concentration of $500 \mathrm{mg} / \mathrm{L}$ by bath sonication of a graphite oxide solution for 1h (Fig. 1c). Fig. 1d shows the UV absorbance spectra of GO dispersions as a function of the GO concentration, clearly showing a stable dispersion of GO nanoplatelets in solvents. Because of their 2D, open structure, GO nanoplatelets can be cut into small-sized nanoplatelets during exfoliation by sonication [12]. The GO size distribution can therefore be widened by increasing the sonication power and time during the exfoliation of graphite oxide. The average size of the unsorted GO exceeded one micrometer. Importantly, we attempted to sort the GO nanoplatelets according to size with a GO suspension by using a centrifugal method.

The $\mathrm{GO}$ dispersions in $\mathrm{H}_{2} \mathrm{O}, \mathrm{KOH}$, and DMF were centrifuged at $10000 \mathrm{rpm}$ for $1 \mathrm{~h}$. The first supernatant solution was decanted and is denoted here as S1. The sediment was redispersed in each solvent by sonicating the suspension for $5 \mathrm{~min}$ (such a short time was used to minimize damage), and the solution was then centrifuged at $10000 \mathrm{rpm}$ for $1 \mathrm{~h}$ to obtain a second supernatant (S2). The third (S3) and fourth (S4) supernatant solutions were prepared using the same procedure. Fig. 2 shows the obtained supernatant solutions, which are light brown in color. Further centrifugation produced a lighter brown supernatant solution. The centrifuged supernatant solutions had different GO concentrations. Comparing S1 solutions in different solvents, $\mathrm{S} 1$ from $\mathrm{H}_{2} \mathrm{O}$ shows a darker brown color than $\mathrm{S} 1$ solutions from DMF and $\mathrm{KOH}$ solutions. This indicates that the GO nanoplatelets that are slightly reduced by the dispersion solvent are easily precipitated by the centrifugal process. SEM images 
(a)

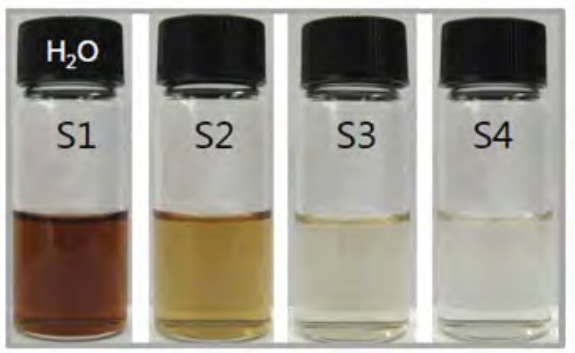

(b)

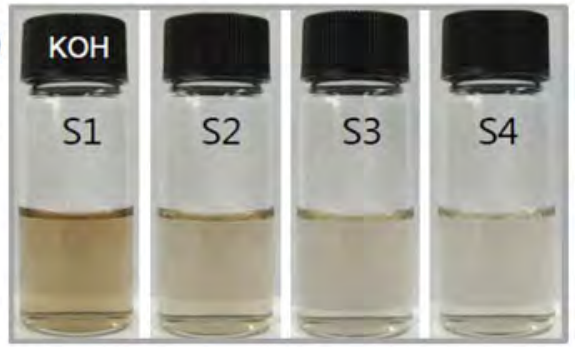

(c)

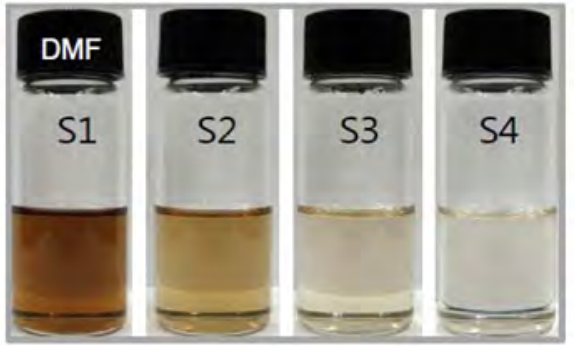

Fig. 2. Photo images of separated graphene oxide dispersion in (a) deionized water $\left(\mathrm{H}_{2} \mathrm{O}\right)$, (b) alkali solution (potassium hydroxide, $\left.\mathrm{KOH}\right)$, (c) dimethylformamide (DMF) from S1 to $\mathrm{S} 4$ by centrifugal methods. of the sorted GO nanosheets, as shown in Fig. 3, revealed that S1 contained small-sized GO (below $1 \mu \mathrm{m}$ ), and the size increased to several micrometers upon further centrifugation. The size distribution could be controlled by varying the centrifugal force and time, with a higher centrifugal force resulting in smaller GO nanoplatelets. However, in the case of the $\mathrm{KOH}$ solution, the sizes of separated GO nanoplatelets from S1 to S4 were not distinguishable, in contrast to $\mathrm{H}_{2} \mathrm{O}$ and the DMF solution.

It is worth noting that the surface chemistry of the GO nanoplatelets was significantly influenced by the solvents used to disperse them. DMF, alcohol or alkali solution can reduce GO nanoplatelets in solution depending on the temperature and time [17-19]. Moderate heating during exfoliation of graphite oxide by using a sonicator or a homogenizer can reduce the exfoliated GO nanoplatelets. In the case of alkaline solution, the deoxygenation reaction depends on the $\mathrm{pH}$-the higher the $\mathrm{pH}$ of the exfoliated-GO dispersion, the faster the reaction [19]. The XPS spectra of separated GO nanoplatelets are presented in Fig. 4. The $\mathrm{C} / \mathrm{O}$ atomic ratio is an important parameter for evaluating the degree of oxidation of GO sheets. The $\mathrm{C} 1 \mathrm{~s}$ spectra were compared by deconvoluting each spectrum into three peaks. The $\mathrm{C} 1 \mathrm{~s}$ spectra of the unsorted GO nanoplatelets showed peaks at 284.6, 286.6, and $288.1 \mathrm{eV}$, which corresponded to $\mathrm{C}=\mathrm{C} / \mathrm{C}-\mathrm{C}(51.6 \%)$, $\mathrm{C}-\mathrm{O}(39.5 \%)$, and $\mathrm{C}=\mathrm{O}(8.9 \%)$ chemical bonding states, respectively. Separated S1- and S3-GO nanoplatelets dispersed in $\mathrm{H}_{2} \mathrm{O}$ show a similar $\mathrm{C} / \mathrm{O}$ ratio, while $\mathrm{S}-3 \mathrm{GO}$ in DMF shows more reduced characteristics. Importantly, from the alkaline solution, the $\mathrm{COOH}$ groups, among several different oxygenated groups, were dominant in the separated GO nanoplatelets in terms of relative percentage. This is due to the stabilization of the carboxylic acid group by potassium ions. This means that the highly
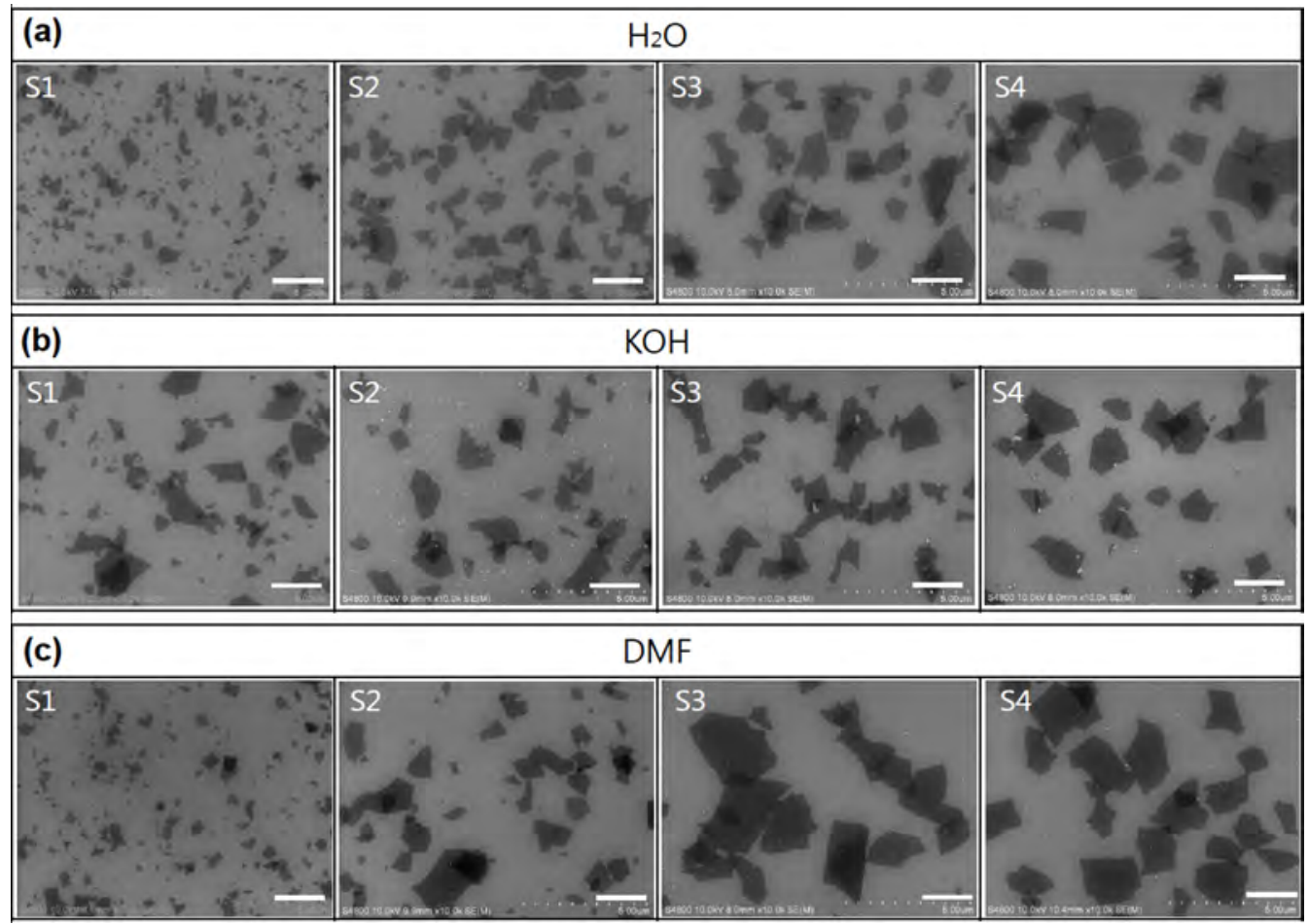

Fig. 3. Scanning electron microscopy images of separated graphene oxide nanoplatelets (from $\mathrm{S} 1$ to $\mathrm{S} 4$ ) using (a) $\mathrm{H}_{2} \mathrm{O}$, (b) potassium hydroxide (KOH) (c) dimethylformamide (DMF) as dispersion solvents. Scale bars indicate $2 \mu \mathrm{m}$. 

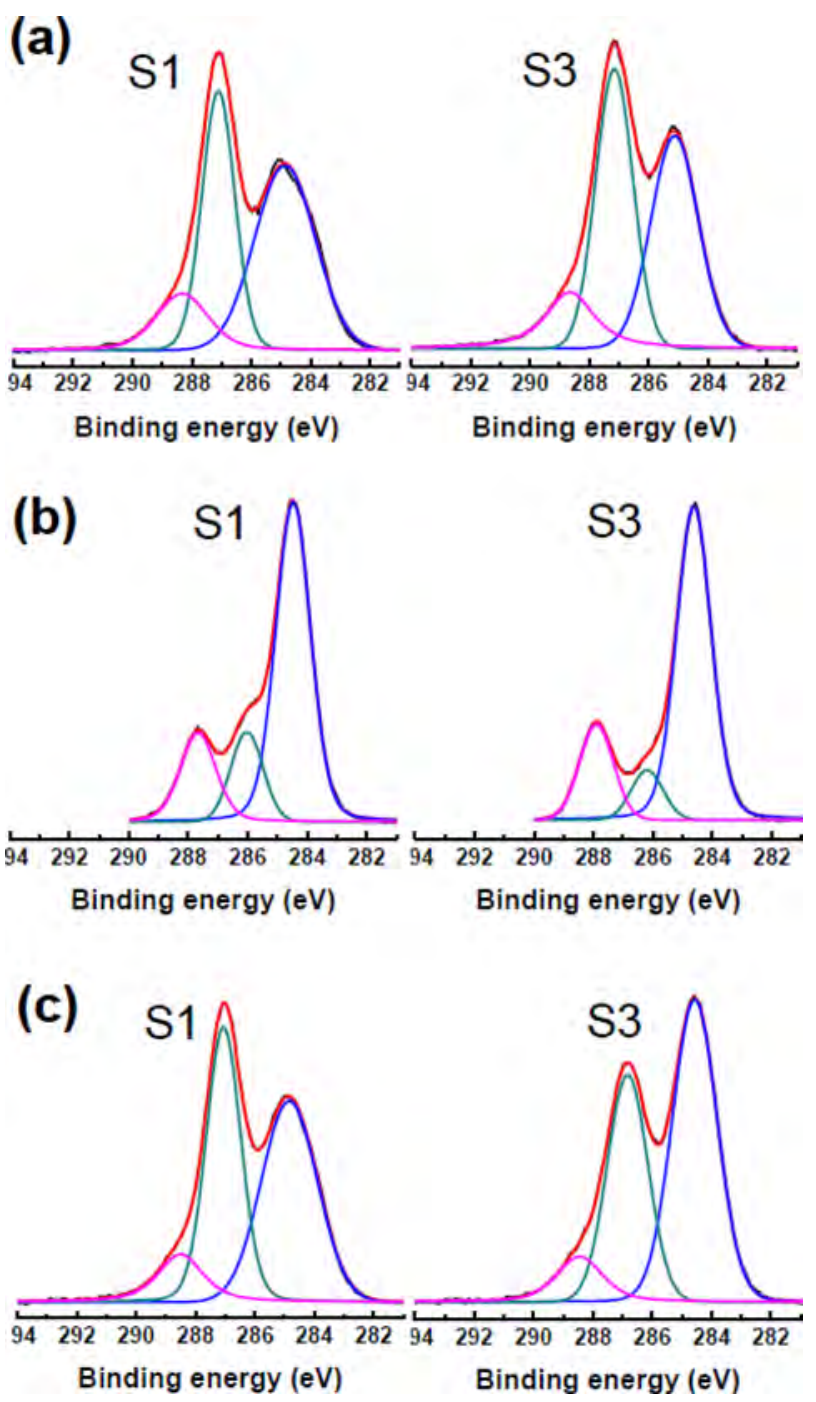

Fig. 4. X-ray photoelectron spectroscopy spectra of separated graphene oxide nanoplatelets $(\mathrm{S} 1, \mathrm{~S} 3)$ using $(\mathrm{a}) \mathrm{H}_{2} \mathrm{O}$, (b) potassium hydroxide (c) dimethylformamide as dispersion solvents. negative charged GO nanoplatelets can be selectively separated by the centrifugal method.

The G-band in Raman spectroscopy is active in sp2-hybridized carbon-based materials, while the D-band is activated when defects participate in double resonance Raman scattering near the $\mathrm{K}$ point of the Brillouin zone. Thus, the D- to G-band peak intensity ratio, $\mathrm{I}_{\mathrm{D}} / \mathrm{I}_{\mathrm{G}}$, is often used to indicate defects in a given structure. Fig. 5 shows Raman spectra of unsorted GO and separated GO nanoplatelets. It is worth noting that the D band intensities were not substantially different from S1 to S4 in all samples. These results indicate that defects in the basal plane are not significantly different from S1 to S4. Moreover, defects caused by edge boundaries were not observed in our samples, in contrast to the decreased $\mathrm{I}_{\mathrm{D}} / \mathrm{I}_{\mathrm{G}}$ observed/reported for ultra-large GO nanoplatelets $\left(>100 \mu \mathrm{m}^{2}\right)[20]$.

\section{Conclusions}

In this study, we systematically investigated the effects of solvents on the size-sorting of GO nanoplatelets by a centrifugal method. To do this, we first oxidized graphite by the Hummers method and separated the highly oxidized graphite oxide. The graphite oxide was then exfoliated into GO nanoplatelets in distilled water, alkali solution, or DMF for the size sorting process. Significantly, we found that distilled water was the most efficient medium to separate the small-sized GO nanoplatelets. Meanwhile, in the alkali solution, most of the GO nanoplatelets were precipitated by 10000 rpm centrifugation because of partial reduction of GO in the alkali condition during the exfoliation and separation processes.

\section{Acknowledgements}

This work was supported by a grant from the Fundamental R\&D Program for Core Technology of Materials funded by the Ministry of Knowledge Economy (MKE), the IT R\&D Program of MKE/KEIT, and the Center for Advanced Soft Electronics under the Global Frontier Research Program of the Ministry of Education, Science and Technology,
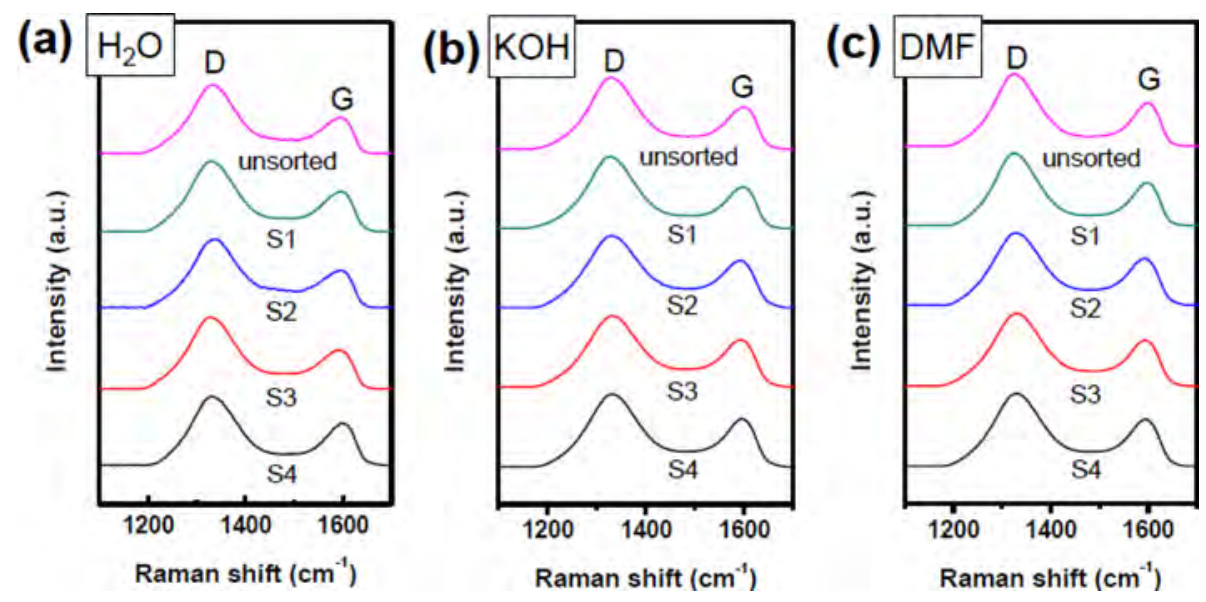

Fig. 5. Raman spectra of separated graphene oxide nanoplatelets (from $\mathrm{S} 1$ to $\mathrm{S} 4$ ) using (a) $\mathrm{H}_{2} \mathrm{O}$, (b) potassium hydroxide (KOH) (c) dimethylformamide (DMF) as dispersion solvents. 


\section{References}

[1] Stankovich S, Dikin DA, Dommett GHB, Kohlhaas KM, Zimney EJ, Stach EA, Piner RD, Nguyen ST, Ruoff RS. Graphenebased composite materials. Nature 442, 282 (2006). http://dx.doi. org/10.1038/nature04969.

[2] Gilje S, Han S, Wang M, Wang KL, Kaner RB. A chemical route to graphene for device applications. Nano Lett, 7, 3394 (2007). http:// dx.doi.org/10.1021/n10717715.

[3] Wang G, Yang J, Park J, Gou X, Wang B, Liu H, Yao J. Facile synthesis and characterization of graphene nanosheets. J Phys Chem C, 112, 8192 (2008). http://dx.doi.org/10.1021/jp710931h.

[4] Eda G, Fanchini G, Chhowalla M. Large-area ultrathin films of reduced graphene oxide as a transparent and flexible electronic material. Nat Nanotechnol, 3, 270 (2008). http://dx.doi.org/10.1038/ nnano.2008.83.

[5] Becerril HA, Mao J, Liu Z, Stoltenberg RM, Bao Z, Chen Y. Evaluation of solution-processed reduced graphene oxide films as transparent conductors. ACS Nano, 2, 463 (2008). http://dx.doi. org $/ 10.1021 / \mathrm{nn} 700375 \mathrm{n}$.

[6] Si Y, Samulski ET. Synthesis of water soluble graphene. Nano Lett, 8, 1679 (2008). http://dx.doi.org/10.1021/n1080604h.

[7] Park S, Ruoff RS. Chemical methods for the production of graphenes. Nat Nanotechnol, 4, 217 (2009). http://dx.doi.org/ 10.1038/ nnano.2009.58.

[8] Han JT, Kim BJ, Kim BG, Kim JS, Jeong BH, Jeong, SY, Jeong HJ, Cho JH, Lee GW. Enhanced electrical properties of reduced graphene oxide multilayer films by in-situ insertion of a $\mathrm{TiO}_{2}$ layer. ACS Nano, 5, 8884 (2011). http://dx.doi.org/10.1021/nn203054t.

[9] Jeong SY, Kim SH, Han JT, Jeong HJ, Yang SH, Lee GW. Highperformance transparent conductive films using rheologically derived reduced graphene oxide. ACS Nano, 5, 870 (2011). http:// dx.doi.org/10.1021/nn102017f.

[10] Jeong SY, Kim SH, Han JT, Jeong HJ, Jeong SY, Lee GW. Highly concentrated and conductive reduced graphene oxide nanosheets by monovalent cation $-\pi$ interaction: toward printed electronics. Adv Funct Mater, 22, 3307 (2012). http://dx.doi.org/10.1002/ adfm. 20 .

[11] Han JT, Jang JI, Jeong BH, Kim BJ, Jeong SY, Jeong HJ, Cho $\mathrm{JH}$, Lee GW. Spontaneous reduction and dispersion of graphene nano-platelets with in situ synthesized hydrazine assisted by hexamethyldisilazane. J Mater Chem, 22, 20477 (2012). http://dx.doi. org/10.1039/c2jm34691e.

[12] Jeong HJ, Jeong HD, Kim HY, Kim SH, Kim JS, Jeong SY, Han JT, Lee GW. Flexible field emission from thermally welded chemically doped graphene thin films. Small, 8, 272 (2012). http://dx.doi. org 1 10.1002/smll.201101696.

[13] Zhu J, Lee CH, Joh HI, Kim HC, Lee S. Synthesis and properties of polyimide composites containing graphene oxide via insitu polymerization. Carbon Lett, 13, 230 (2012). http://dx.doi org/10.5714/CL.2012.13.4.230.

[14] Kim J, Park SJ, Kim S. Capacitance behaviors of polyaniline/ graphene nanosheet composites prepared by aniline chemical polymerization. Carbon Lett 14, 51 (2013). http://dx.doi.org/10.5714/ CL.2013.14.1.051.

[15] Park S, Hu Y, Hwang JO, Lee ES, Casabianca LB, Cai W, Potts JR, Ha HW, Chen S, Oh J, Kim SO, Kim YH, Ishii Y, Ruoff RS Chemical structures of hydrazine-treated graphene oxide and generation of aromatic nitrogen doping. Nat Commun, 3, 638 (2012) http://dx.doi.org/10.1038/ncomms 1643 .

[16] Han JT, Kim JS, Jo SB, Kim SH, Kim JS, Kang B, Jeong HJ, Jeong SY, Lee GW, Cho K. Graphene oxide as a multi-functional p-dopant of transparent single-walled carbon nanotube films for optoelectronic devices. Nanoscale, 4, 7735 (2012). http://dx.doi. org/10.1039/c2nr31923c

[17] Ai K, Liu Y, Lu L, Cheng X, Huo L. A novel strategy for making soluble reduced graphene oxide sheets cheaply by adopting an endogenous reducing agent. J Mater Chem, 21, 3365 (2011). http:// dx.doi.org/10.1039/c0jm02865g.

[18] Dreyer DR, Murali S, Zhu Y, Ruoff RS, Bielawski CW. Reduction of graphite oxide using alcohols. J Mater Chem, 21, 3443 (2011). http://dx.doi.org/10.1039/c0jm02704a .

[19] Fan X, Peng W, Li Y, Li X, Wang S, Zhang G, Zhang F. Deoxygenation of exfoliated graphite oxide under alkaline conditions: a green route to graphene preparation. Adv Mater, 20, 4490 (2008). http://dx.doi.org/10.1002/adma.200801306

[20] Lin X, Shen X, Zheng Q, Yousefi N, Ye L, Mai YW, Kim JK. Fabrication of highly-aligned conductive and strong graphene papers using ultralarge graphene oxide sheets. ACS Nano, 6, 10708 (2012). http://dx.doi.org/10.1021/nn303904z. 